\title{
SURGICAL TREATMENT OF ENDOCRINE EXOPHTHALMOS BY REMOVAL OF ORBITAL FAT: CLINICAL EXPERIENCE
}

\author{
Marcus Castro Ferreira, Paulo Tuma Jr., Márcio Paulino Costa, Walter Bloise \\ and Carlos Alberto Rodrigues Alves
}

RHCFAP/3096

FERREIRA MC et al. - Surgical treatment of endocrine exophthalmos by removal of orbital fat: clinical experience. Rev.

Hosp. Clín. Fac. Med. S. Paulo 57(5):217-222, 2002.

PURPOSE: To report a series of 73 patients with endocrine exophthalmos treated by removal of orbital fat using the transpalpebral approach during the period 1989 to 1999.

METHODS: The operation was performed according to the technique described by Olivari. Aesthetic analysis was done preoperatively and postoperatively (more than 6 months after surgery). The number of complications was also observed.

RESULTS: The average volume of resected fat was approximately $7.6 \mathrm{~mL}$ per orbit. No major complication was observed. In 9 patients with epiphora, all improved. One patient developed postoperative diplopia and 5 complained of temporary diplopia. Appearance improved in 62 patients $(85 \%)$.

CONCLUSION: Surgical removal of orbital fat associated with endocrine exophthalmos provides consistent improvement in appearance with a low rate of complications. Additional procedures may be indicated to improve the cosmetic outcome.

DESCRIPTORS: Endocrine exophthalmos. Transpalpebral surgery. Orbital fat.

\section{INTRODUCTION}

Endocrine exophthalmos is a syndrome that appears in some patients with thyroid disease. Although there are many signs included in the syndrome, only bilateral proptosis and eyelid retraction are pathognomonic. The "lid lag" with stare when looking downwards is typical, but it can appear in other diseases. Graves' diseases is the most common cause of exophthal$\operatorname{mos}^{1-4}$.

Indication for surgery has been traditionally determined considering progressive loss of visual acuity, degree of systemic thyroid disease, and impairment of extraocular muscle function, either fibrotic or inflammatory. Moderate or severe ocular impairment in thyroid disease is uncommon; less than $5 \%$ of patients require surgical treatment. More recently, aesthetic concern has become a main motivation for surgical treatment.

Classical surgical techniques are comprised of the many forms of orbital decompression, done through osteotomy of the orbital walls. Orbital decompression has been the preferred method for surgical correction of severe forms of disease $\mathrm{e}^{5-7}$.

Some authors have included aesthetic concern among the indications for orbital decompression ${ }^{\mathbf{8}, 9}$. A number

From the Division of Plastic Surgery, Hospital das Clínicas, Faculty of Medicine, University of São Paulo. of postoperative complications were reported in association with this rather extensive procedure, including paresthesia in the area of infraorbital branch innervation ${ }^{5,7}$, diplopia because of a misalignment of extraocular muscles, oculomotor disorders varying from $30 \%$ to $70 \%$ of strabismus in some series ${ }^{7}$, globe ptosis, and less frequently, lesion of the nasolacrimal duct, liquor fistula, and sinusitis ${ }^{2}$.

For the variation of exophthalmos that is without a major functional indication, the dissatisfaction with any type of bone removal technique is clear, and most patients prefer simply not to be surgically treated. In 1988, Olivari reported a new procedure for correction of exophthalmos that involved only removing orbital fat and 
thus had no need of bone surgery ${ }^{10-12}$.

Despite the clear advantages of this approach, the technique has not gained widespread acceptance in clinical practice in our country and remains almost unknown in most centers.

We started using this technique of orbital fat removal in 1989 in the Hospital das Clinicas, and the initial cases were published in $1992^{4}$.

We report now a larger series, treated during the last 10 years, to more extensively discuss the technique, the results, and the complications.

\section{METHODS}

From 1989 to 1999,73 patients with bilateral exophthalmos associated with Graves' disease were surgically treated. Sixty-one were female and 12 male, with ages ranging between 24 and 52 years.

The patients were always referred for surgical treatment after being considered stable for more than 1 year after treatment of thyroid disease.

Eighty percent of the patients had grade III exophthalmos (proptosis of 3 $\mathrm{mm}$ or more, with or without eyelid swelling), and $20 \%$ had grade IV (involvement of extraocular muscles, usually with diplopia, limitation of movement in extreme positions, and evident restriction of movement. There was no severe impairment of vision in any case.

All patients complained of aesthetic disturbance with associated psychological problems involving an inferiority complex. The dissatisfaction with their facial appearance was important and related to difficulties in their professional and personal relationships.

\section{SURGICAL PROCEDURE}

The operation was performed under general anesthesia in all cases. The up- per eyelid was opened through a conventional blepharoplasty incision. The orbicular muscle was divulsed, and the orbital septum split to expose the superficial orbital fat pouches (lateral and medial), which were resected as deeply as possible, with care to avoid injuring the lacrimal nerve laterally, and in the medial area, the supraorbital nerve. Hemostasis was done only with a bipolar coagulator, and magnifying loupes were used.

The lower lid was then incised about $1 \mathrm{~mm}$ from the lid margin. After divulsing the eyelid orbicular muscle, the orbital septum was reached and then incised. Fat was removed from lateral to medial pouches until the inferior oblique muscle was exposed. At this point, the fat pouches were divided into 2 parts to avoid injuring the muscle and its innervation.

Aspiration drains were used for 48 hours. The procedure was performed on only 1 orbit at a time, with the other being carried out after at least 45 days.

The volumes of fat resected from the upper and lower lids were verified, and the total volume was computed. No skin was removed from the eyelid in any case.

In 46 patients who had significant a degree of retraction of the lower lid, a cartilage graft was used, which was removed from the auricular concha and fixed on the tarsus with 2 or 3 stitches of 5-0 nylon.

In 15 patients with retraction of the upper lid, the aponeurosis of the muscle levator palpebrae was incised partially to elongate the muscle.

The aesthetic result was accessed by both surgeon and patient during the preoperative and postoperative periods (more than 6 months after surgery). Aesthetics were graded as much improved, improved, not improved, or worsened.

The number of complications related to the procedure was also documented.

\section{RESULTS}

The average volume of resected fat was approximately $7.6 \mathrm{~mL}$ per orbit, with a maximum of $11.5 \mathrm{~mL}$ and a minimum of $2.0 \mathrm{~mL}$.

No severe postoperative complication was observed, such as loss of vision, retrobulbar hematoma, infection, paresthesia on the infraorbital nerve territory, damage to the lacrimal duct, liquor fistula, sinusitis, or ptosis of the eyeball.

Preexisting epiphora in 9 patients improved after the operation. Seven patients developed postoperative diplopia for up to 3 months; 1 patient developed more durable diplopia. In 2 patients who already had diplopia, no worsening was observed.

Regarding the aesthetic result, 29 patients said that their appearance was much improved after the operation, and the same opinion was expressed by the surgeon; 23 were considered improved, and for 11 there was no major aesthetic gain, although there was no worsening either. The aesthetic aspect of the cartilage grafts, which were somewhat visible, and residual upper lid shortening were the most common reasons for dissatisfaction; fullness of eyelids was not a factor producing dissatisfaction.

\section{DISCUSSION}

Patients with hyperthyroidism may develop endocrine ophthalmopathy in $40 \%$ of the cases, and the condition is frequently resistant to conservative therapy, which provides no more than small regression ${ }^{12}$.

The use of steroids can be helpful in the acute phase of the process ${ }^{2,3}$, although steroids do not change the degree of exophthalmos and may cause undesirable side effects, such as weight gain or hypertension. Retrobulbar radiotherapy is indicated only in severe 


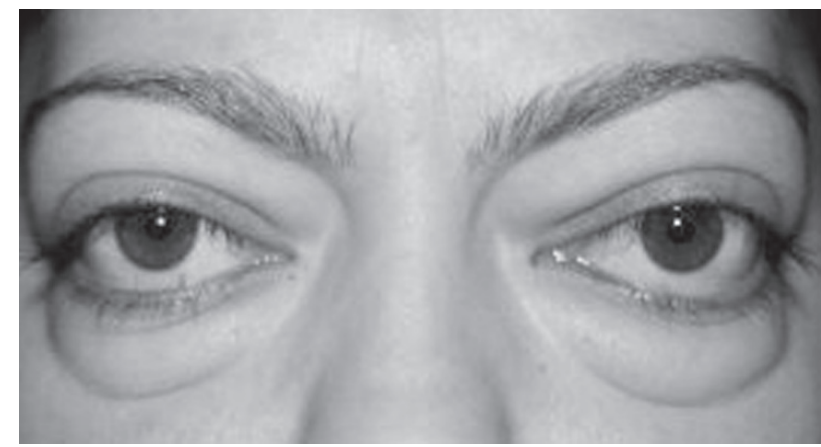

Figure 1 - a) and b) Preoperative - aspect of exophthalmos

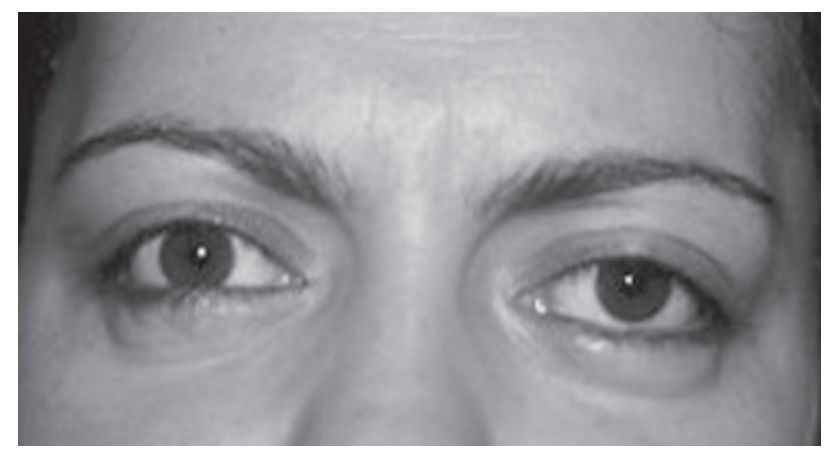

Figure 2 - a) and b) Postoperative - result after 2 years. Removal of fat plus cartilage graft

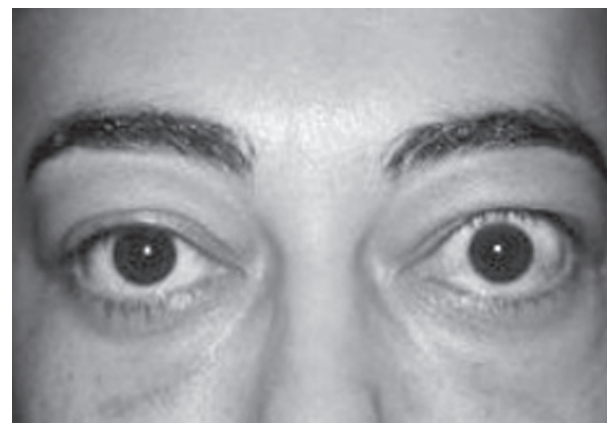

Figure 3 - Preoperative aspect

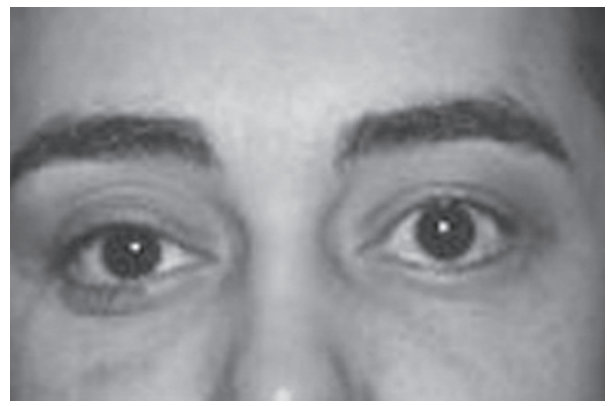

Figure 4 - Postoperative - after 2 years

and progressive exophthalmos, and even then, it was reported to be partially successful only if performed within the first 6 months after the on- set of the disease. In chronic endocrine ophthalmopathies, conservative therapy - particularly radiation therapy - is not effective at all ${ }^{11}$.
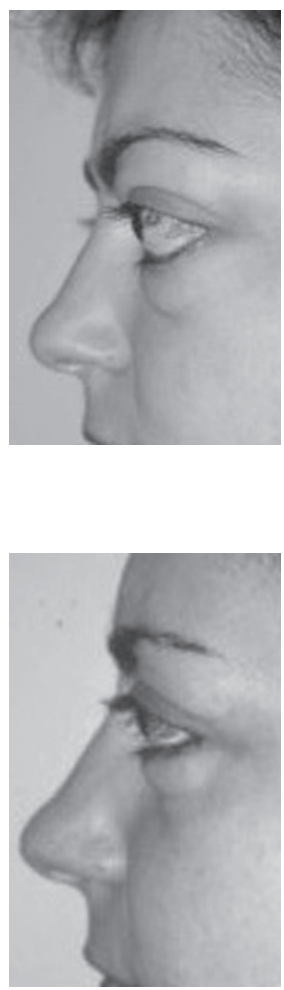

In the stable exophthalmos, appearance is the most important concern for the patient, and surgical treatment should be considered. Procedures described for severe cases, such as the orbital decompression using osteotomies of the orbital walls, either on the inferior and medial walls ${ }^{\mathbf{1 3}, 14}$, have no indication for these cases because of the rate of reported complications $\mathrm{s}^{2,5,6,7,12,13}$. For that reason, osteotomy of the orbital wall is rarely used in Brazil, except in severe cases when there is risk of vision loss (malignant exophthalmos).

In the majority of the cases with aesthetic dissatisfaction, the patient preferred not to undergo radical orbital osteotomies and asked for a less aggressive approach. After the experience of Olivari ${ }^{10}$, we in Brasil started in 1989 to use the technique of transpalpebral removal of orbital fat ${ }^{4}$.

In this last decade, we have learned, with this clinical experience of 73 patients, that although the operation for resection of orbital fat is more extensive when compared with the aesthetic 
blepharoplasty, it is still a relatively non-invasive procedure and is not followed as we initially feared by complications, such as retrobulbar hematoma, infection, fistula, or blindness. Our results are similar to those reported lately by Olivari and others ${ }^{11,12,15,16}$. No infraorbital nerve parestesia was observed, a finding that is rather common after orbital decompression through osteotomy ${ }^{5,7,13,17}$. However, there is a learning curve, and this procedure should only be performed by an experienced surgeon with additional training in microsurgery.

Only 1 patient developed diplopia that did not improve after the operation. This can be associated with anatomical changes in the extraocular muscles, which were thick and fibrous and become stretched after the procedure due to the content-container relationship, which prevented its new accommodation. Five patients had postoperative temporary diplopia that improved with time; this rate of occurrence is consistent rates reported in the literature ${ }^{12}$. Temporary diplopia may be related to the fact that the operation was performed in one orbit at a time, but data is not conclusive at this point. With more confidence on the technique, we are planning to operate on both orbits at the same time in selected cases.

Epiphora improved because the cornea was less exposed postoperatively. In some cases, the cartilage graft was important for correcting the lid retraction and the ectropion. In our initial cases, cartilage grafting was performed as another procedure after some months when the lid retraction was already defined; but lately, we have performed cartilage grafting in the same operation.

Strabismus, when present preoperatively, was not changed after surgery. It has never occurred as a complication, an important consideration, since we know that the rate of this complication after osteotomy was reported to be as high as $70 \% \%^{2,6,18}$.

Aesthetics, as pointed out, was the main motivation for patients who asked for the operation. Evaluation of results after any aesthetic procedure is not an easy task, since there is still no widely accepted method to assess aesthetics. It is been said that the outcome would be similar to the evaluation of an object of art. A subjective aesthetic judgment of the patient or the surgeon is required, which is insufficiently controlled to reach the status of "scientific" criteria.

Patients with endocrine exophthalmos present many variables that concur to comprise the "unaesthetic" appearance-namely, eye enlargement and proptosis and the association with other conditions, such as eyelid retraction, ptosis, scleral show, strabismus, or ectropium.

It was impossible to accurately assess the aesthetic improvement achieved by the removal of fat; therefore, we considered the degree of satisfaction of patients after all the surgical stages. The surgeon was also called on to give his opinion.

Accordingly, although the amount of removed fat was significant in each case (an average of $7.6 \mathrm{~mL}$ per orbit), there is important personal variation among the patients; consequently, treatment should be customized for each patient.

Probably the most important factor for the aesthetic prognosis after the operation is the relationship between the volume of enlarged fat deposits and that of the extraocular muscles. Both are known to be increased in exophthalmos ${ }^{12}$, but in some patients, the fat component is more significant, whereas in others the volume of the muscle is mainly responsible for the protrusion.

Removal of fat is more properly in- dicated in the cases in which the fat volume prevails; this can be detected by tomography and by magnetic resonance, but it is still not always possible, and assessment is not done routinely. In our study, even in the muscle enlargement group, the reduction of stasis resulting from the removal of fat from the orbit helped produce a regression of edema in the extraocular muscles, and thus secondarily produced a reduction in the protrusion.

Other complementary procedures can be used; however, an extensive list of procedures is a discussion beyond the scope of this paper. Even Olivari ${ }^{12}$ has not discussed extensively all the aesthetic features related to this syndrome. Most patients had some complementary operations done, the results after cartilage grafts being the most impressive.

Cartilage grafts from concha as a spacer for the lower lid can be performed at the same time or subsequent to the orbital decompression and were not part of the original technique described by Olivari ${ }^{10}$, but are frequently used nowadays for several other plastic surgery indications.

The results obtained with this type of procedure should not be compared with orbital decompression methods through osteotomy, because the indications are not the same. In our view, bony orbital decompression should not be performed if the indication is mostly aesthetic.

Our experience with the technique of fat resection for the treatment in the endocrine exophthalmos showed that there was aesthetic improvement in most cases as evaluated both by the patient and the surgeon. The final aesthetic result can be satisfactory, but other plastic surgery procedures, such as canthoplasties, cartilage grafts, and treatment of a levator palpebrae disturbance, may be necessary to improve the result. 
FERREIRA MC e col. - Tratamento cirúrgico do exoftalmo endócrino por remoção da gordura orbitária: experiência clínica. Rev. Hosp. Clín. Fac. Med. S. Paulo 57(5): 217-222, 2002.

OBJETIVO: Apresentamos uma série de 73 pacientes com exoftalmo endócrino tratados pela Divisão de Cirurgia Plástica do Hospital das Clínicas da Faculdade de Medicina da Universidade de São Paulo, através da remoção da gordura orbitária usando acesso transpalpebral, durante o perío- do de 1989 a 1999.

MÉTODOS: A avaliação foi realizada através de análise estética, no pré e no pós-operatório (maior do que seis meses). O número de complicações também foi mensurado. Nove pacientes apresentaram epífora, todos com melhora espontânea. Um paciente desenvolveu diplopia no pós-operatório, e cinco apresentaram diplopia temporária. A aparência melhorou em 62 pacientes $(85 \%)$. Uma retroposição média de 2,74 mm foi observada, apesar de o método não ser mais considerado relevante para avaliação de exoftalmo.

CONCLUSÃO: Esta abordagem, ainda não usada rotineiramente no Brasil, constitui uma nova via de acesso para o tratamento do exoftalmo endócrino. Os resultados foram consistentes, com baixo índice de complicações. Outros procedimentos devem sempre ser realizados, visando à melhora dos resultados estéticos.

DESCRITORES: Exoftalmo endócrino. Cirurgia transpalpebral. Gordura orbitária.

\section{REFERENCES}

1. AlveS, C. A. R.; CARVAlHO, C. A. Contribuição ao estudo do comportamento da pressão intra-ocular em portadores de exoftalmo endócrino. Rev Bras de Oftal 1974; 33:93-130.

2. CHAR, D. H. Thyroid eye disease. New York Churchile. Livingstone, 1990.

3. FELLS, P. Thyroid-associated eye disease: clinical management. Lancet 1991; 338:29-32.

4. FERREIRA, M. C.; BONAMICHI, G. T.; TUMA JR., P. et al. Tratamento do exoftalmo residual pela ressecção de gordura orbitária. Rev Hosp Clin Fac Med S Paulo 1992; 47: 258-60.
5. Alves C. A. R.; CASTRO, D. J. L. S.; BARBOSA, I. C. F Exoftalmo endócrino e descompressão orbitária. Rev Bras Oftal 1969; 83: 683-94.

6. GOLDWING-WOOD, P. H. Trans-antral ethmoid decompression in malignant exophthalmos. J Laryngol 1969; 83:683-94.

7. BAYLIS, H. I.; BRANSON-CALL, N.; SHOBATA, G. S. The transastral orbital decompression (Ogura technique) as performed by the ophthalmologist. Ophthalmology 1980; 87:1005-12. 
8. OGURA, J. H.; LUCENTE, F. E. Surgical results of orbital decompression for malignant exophthalmos. Laryngoscope 1974; 84: 637-44

9. SHORR, N.; NEUHAUS, R. W.; BAYLIS, H. I. Ocular motility problems after orbital decompression for dysthyroid ophthalmopathy. Ophthalmology 1982; 89:323-28.

10.OLIVARI, N. Transpalpebrale Dekompressionsoperation bei endokriner Orbitopathie (exophthalmus). Wien Med Wochenschr 1988; 18: 452-55.

11.OLIVARI, N. Transpalpebral decompression of endocrine ophthalmopathy (Graves ' disease) by removal of intraorbital fat: experience with 147 operations over 5 years. Plast Reconstr Surg 1991; 87: 627-41.

12.OLIVARI, N. Endocrine Ophthalmopathy - Surgical treatment. Heidelberg, Kaden Verlog 2001.

13.WALSH, T. E.; OGURA, J. H. Transantral orbital decompression for malignant exophthalmos. Laryngoscope 1957; 65: 54468.
14.MCCORD JR., C. D.; MOSES, J. L Exposure of the inferior orbit with fornix incision and lateral canthotomy. Ophthalmic Surg 1979; 10: 53-63.

15.STARK B.; OLIVARI, N. Management of thyroid orbitopathy by removal of orbital fat; a long-term followup. Eur J Plast Surg 1996; 19:1-6.

16.STARK B.; OLIVARI, N. Orbital de compression by removal of orbital fat. In: van der Menlen, J.C., Gross, J.S (ed) ocular plastic surgery. London Wosby Wolfe, 1996; 123-130.

17.DE SANTO, L. W.; GORMAN. C. A. Selection of patients and choice of operation for orbital decompression in graves ophthalmopathy. Laryngoscope 1973; 83:945-959.

18.TROKEL, S. L.; COOPER, W. C. Orbital decompression effect on motility and globe position. Ophthalmology 1979; 86: 206470 .

19.ALVES, C. A. R. Contribuição ao estudo da exoftalmetria: resultado de 704 medições com o exoftalmômetro de Hertel. Arq Bras Oftalm 1983; 46:5-10.

Received for publication on April 11, 2002. 